\title{
Papers
}

\section{Effects of a medical emergency team on reduction of incidence of and mortality from unexpected cardiac arrests in hospital: preliminary study}

Michael D Buist, Gaye E Moore, Stephen A Bernard, Bruce P Waxman, Jeremy N Anderson, Tuan V Nguyen

\begin{abstract}
Objectives To determine whether earlier clinical intervention by a medical emergency team prompted by clinical instability in a patient could reduce the incidence of and mortality from unexpected cardiac arrest in hospital.

Design A non-randomised, population based study before (1996) and after (1999) introduction of the medical emergency team.

Setting 300 bed tertiary referral teaching hospital. Participants All patients admitted to the hospital in 1996 (n=19 317) and 1999 (n=22 847).

Interventions Medical emergency team (two doctors and one senior intensive care nurse) attended clinically unstable patients immediately with resuscitation drugs, fluid, and equipment. Response activated by the bedside nurse or doctor according to predefined criteria.

Main outcome measures Incidence and outcome of unexpected cardiac arrest.

Results The incidence of unexpected cardiac arrest was 3.77 per 1000 hospital admissions (73 cases) in 1996 (before intervention) and 2.05 per 1000 admissions (47 cases) in 1999 (after intervention), with mortality being $77 \%$ (56 patients) and 55\% (26 patients), respectively. After adjustment for case mix the intervention was associated with a $50 \%$ reduction in the incidence of unexpected cardiac arrest (odds ratio $0.50,95 \%$ confidence interval 0.35 to 0.73 ).

Conclusions In clinically unstable inpatients early intervention by a medical emergency team significantly reduces the incidence of and mortality from unexpected cardiac arrest in hospital.
\end{abstract}

\section{Introduction}

Adverse events in hospital associated with medical management are estimated to occur in $4 \%{ }^{1}$ to $17 \%{ }^{2}$ of admissions. Further analyses of such events found that up to $70 \%$ of them were preventable. ${ }^{34}$ One of the more serious and clinically important adverse events is unexpected cardiac arrest. Despite the availability of cardiac arrest teams and advances in cardiopulmonary resuscitation the risk of death from such an event has remained largely static at $50-80 \% .^{5}{ }^{6}$
Unexpected cardiac arrests in hospital are usually preceded by signs of clinical instability. ${ }^{78}$ In a pilot study we noted that $112 \quad(76 \%)$ patients with unexpected cardiac arrest or unplanned admission to intensive care had deterioration in the airway, circulation, or respiratory system for at least one hour (median 6.5 hours, range 0-432 hours) before their index event. ${ }^{9}$ Furthermore, these patients were often reviewed (median twice, range $0-13$ ) by junior medical staff during the documented period of clinical instability. Despite this the hospital mortality for these patients was $62 \%$.

Such patients should receive better assessment either for aggressive resuscitation and management or for clear institution of "do not resuscitate" orders with palliative care. A medical emergency team has been proposed as a pre-emptive response system to manage these patients. ${ }^{910}$ In this system when clinical observations reach certain predefined critical limits the primary care nurse or medical officer calls for the team, which responds immediately. The team in our hospital comprises a medical registrar, an intensive care registrar, and a senior intensive care nurse and is equipped with resuscitation drugs, fluids, and equipment.

\section{Methods}

We carried out a non-randomised investigation in which the incidence of and mortality from cardiac arrest were recorded in inpatients in a single hospital over two 12 month periods: before (1996) and after (1999) the implementation of the intervention. Ethical approval for the study was granted from the Dandenong Hospital ethics committee.

\section{Hospital setting}

Dandenong Hospital is a 300 bed, general metropolitan teaching hospital affiliated to the university. The hospital is part of the southern healthcare network and provides general clinical services (except cardiac surgery, elective neurosurgery, and magnetic resonance imaging) to a suburban population of about 500000 . Each year the emergency department treats about 38000 patients, the hospital has over 20000 inpatients, and there are 500 to 600 admissions to intensive care.

\author{
Departments of \\ Intensive Care and \\ Surgery, \\ Dandenong \\ Hospital, \\ Dandenong, VIC \\ 3175, Australia \\ Michael D Buist \\ director of intensive \\ care unit \\ Gaye E Moore \\ research nurse \\ Stephen A Bernard \\ deputy director of \\ intensive care unit \\ Bruce P Waxman \\ surgical programme \\ director \\ Monash University \\ Institute of Public \\ Health, \\ Jeremy N Anderson \\ associate professor \\ University of New \\ South Wales \\ Department of \\ Anaesthetics, \\ Emergency \\ Medicine and \\ Critical Care, \\ Tuan V Nguyen \\ senior fellow \\ Correspondence to: \\ M Buist \\ acmdbuist@ \\ bigpond.com \\ BMJ 2002;324:1-6
}


Implementation of the system

In 1996 the hospital had a "traditional" system of response to clinically unstable patients. The nurse would observe and document the instability, a call would then be made to the most junior member of the medical team, who would attend the patient, review the problem, and institute treatment. If the patient's condition continued to be unstable, the junior medical officer would seek advice from the next most senior member of the medical team concerned with the patient's management (in our hospital, the specialty registrar). The treatment review cycle could then be repeated, often with referrals to other specialist services. Occasionally, these cycles were further repeated when the consultant reviewed the case and different teams of on-call doctors became involved.

We gradually introduced the medical emergency team into the hospital from 1997, using the same criteria as reported previously. ${ }^{11}$ Initial implementation was only partially successful as the number of calls was low. ${ }^{9}$ We thought this was because junior medical staff were reluctant to broach the "traditional" system of management and nursing staff were reluctant to respond against doctors' orders.

In 1999 we implemented a formal education and audit process directed at junior medical staff and nursing staff after the employment of a full time research nurse. The education process included interactive audiovisual presentations to hospital staff in small groups, attachment to all staff identification badges of the criteria for calling the medical emergency team, and strategic placement of posters throughout the hospital. All calls made to the team in the previous week were reviewed weekly. Staff who were involved in the more important events as identified by the audit were debriefed. Additionally, publication in 1999 of data from our pilot study in 1997 further emphasised the problem of the management of clinically unstable patients in hospital. ${ }^{9}$ During 1997-9 we altered and simplified the criteria for calling the team in response to feedback from primary care nurses and junior medical officers (see box). ${ }^{9}$ The team was not called to the emergency department, operating theatres, or intensive care and coronary care units.

\section{Data collection}

We collected data from 1 January to 31 December 1996 (before the intervention) and from 1 January to 31 December 1999 (after the intervention) (figure). We used two discontinuous time periods because the process of implementation took at least two years and is still ongoing. As data on cardiac arrest calls and hospital population were collected differently in 1994 and 1995 from the rest of the data, these two years were not used in statistical comparisons with data collected from 1996 onwards.

For each cardiac arrest call made during the study periods we recorded demographic data, source, reason, date for admission to hospital, and data necessary for calculating the various severity scores. We reviewed data for completeness by cross referencing documented records of cardiac arrest calls made by the hospital telephone switchboard operators and reviewing all medical records for that year with a discharge code that included the words "cardiac arrest." We adopted a working definition of cardiac arrest-namely, that a
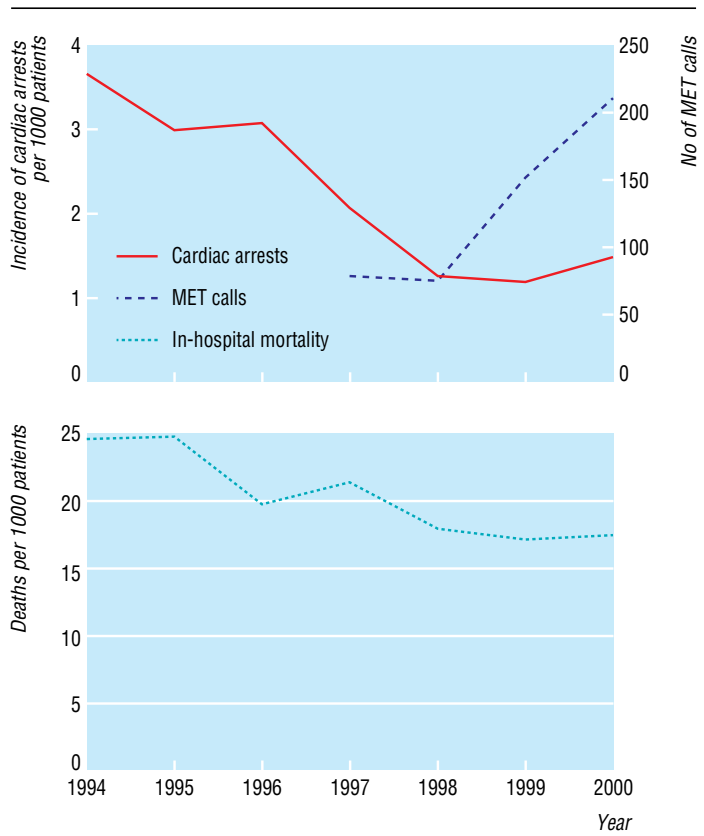

Incidence of cardiac arrests, number of calls to medical emergency team (MET), and in-hospital mortality between 1994 and 2000

staff member was so concerned about a patient that they made a cardiac arrest call, regardless of whether the patient was actually having a cardiac arrest. There were three calls in 1996 and one in 1999 to patients (all of whom died) who had been given "do not resuscitate" orders before the call. As these cardiac arrests were expected the data were not included in the study.

We abstracted data for the total hospital population for the two study periods from the hospital admission database. Each patient was identified by a unique identification number. We analysed data on a patient not an admission basis. All data were linked by the unique identification number.

\section{Statistical analysis}

We described and estimated the incidence of cardiac arrest calls in relation to patients' demographic and

\section{Criteria for calling medical emergency team}

Airway

Respiratory distress

Threatened airway

Breathing

Respiratory rate $>30 / \mathrm{min}$

Respiratory rate $<6 / \mathrm{min}$

$\mathrm{SaO}_{2}<90 \%$ on oxygen

Difficulty speaking

Circulation

Blood pressure $<90 \mathrm{~mm} \mathrm{Hg}$ despite treatment

Pulse rate $>130 /$ min

Neurology

Any unexplained decrease in consciousness

Agitation or delirium

Repeated or prolonged seizures

Other

Concern about patient

Uncontrolled pain

Failure to respond to treatment

Unable to obtain prompt assistance 
clinical characteristics and investigated the independent predictors of calls. In all analyses we used the patient as the sampling unit. We calculated the incidence of cardiac arrest calls per 1000 patients at risk. We used dates of hospital admission, admission to intensive care, and discharge to calculate length of stay in hospital and intensive care. Univariate association of various "risk factors" (for example, age, sex, source of admission, and reason for admission) was evaluated by descriptive statistical techniques, such as $t$ test, $\chi^{2}$ test, non-parametric Mann-Whitney rank sum test, etc, for appropriate data and their probability distributions. We used the generalised estimating equation model to test for difference in severity scores between sources of and reasons for admission to intensive care to account for any multiple admissions. Because of the multiple comparisons in this analysis we set the significance level at 0.001 .

To determine the potential predictors of cardiac arrest calls we used logistic regression to model the probability of a call in relation to patient's age, sex, type of admission, reason for admission, and diagnostic related groups (Commonwealth Department of Health and Family Services, 1999). We included separate interaction terms to detect relations between the presence or absence of the medical emergency team and each of the factors in the model to examine whether the presence of a particular risk factor had a significant impact on the probability of a call before and after the implementation of the intervention. We used stepwise and backward elimination algorithms to identify potential predictors of mortality. To account for multiple admission we used the generalised estimating equation model with Proc Genmod (SAS). ${ }^{12}$

\section{Results}

\section{Hospital admissions}

From 1996 to 1999 the number of hospital admissions increased by $14 \%$, from 25194 before the intervention to 28801 after the intervention. Because there were multiple admissions during the study period the actual number of patients increased by 18\%, from 19317 in 1996 to 22847 in 1999. Table 1 shows the basis characteristics of the patients in the two periods.

When we used the number of admissions as sampling units we found a significant difference in the types of admissions between the two periods. For instance, the number of admissions from the emergency department increased from 52\% in 1996 to $59 \%$ in 1999. Similarly, "planned admissions" increased from $17 \%$ in 1996 to $21 \%$ in 1999 . Table 2 gives data on admissions according to diagnostic related groups.

\section{Incidence and predictors of cardiac arrest calls}

In the two periods there were 73 and 47 unexpected cardiac arrest calls respectively, giving incidences of 3.77 and 2.05 per 1000 patients $(\mathrm{P}<0.001)$. Mortality was $56 / 73(77 \%)$ before the intervention and 26/47 (55\%) after the intervention (difference significant at $\mathrm{P}<0.001$ ) (table 3). There was no significant difference in the actual reasons for the call between the two periods.

We considered all of these factors in a multiple logistic regression model. Presence of the medical emergency team (odds ratio $0.52,95 \%$ confidence interval 0.36 to 0.74$)$; age $\geqslant 65$ years $(8.1,5.3$ to 12.2$)$; admission
Table 1 Basic characteristics of patients before (1996) and after (1999) implementation of medical emergency team

\begin{tabular}{|c|c|c|}
\hline Hospital characteristics & $\begin{array}{c}\text { Before } \\
\text { intervention }\end{array}$ & After intervention \\
\hline No of patients & 19317 & 22847 \\
\hline No of admissions & 25194 & 28801 \\
\hline Proportion of men (\%) & 44.4 & 44.6 \\
\hline Proportion of same day admissions (\%) & 47.7 & 49.2 \\
\hline Mean (SD) age (years) & $36.6(26.0)$ & $36.4(26.0)$ \\
\hline Proportion aged $\geqslant 65$ years & 19.3 & 19.0 \\
\hline \multicolumn{3}{|l|}{ Length of stay (days): } \\
\hline Mean (SD) & $3.6(6.3)$ & $3.9(14.8)^{\star}$ \\
\hline Median (25th, 75th centile) & $2(1,4)$ & $2(1,4)$ \\
\hline \multicolumn{3}{|l|}{ Intensive care: } \\
\hline No of admissions & 435 & 622 \\
\hline No of unplanned admissions & 45 & 78 \\
\hline $\begin{array}{l}\text { Mean (SE) APACHE II score of unplanned } \\
\text { admissions }\end{array}$ & $18.4(1.0)$ & $18.9(1.0)$ \\
\hline \multicolumn{3}{|l|}{ Types of admissions (\%): } \\
\hline Emergency department & $13058(51.8)$ & $16921(58.8)^{*}$ \\
\hline Maternity & $2475(9.8)$ & $2790(9.7)$ \\
\hline Planned & $4237(16.8)$ & $6157(21.4)^{*}$ \\
\hline Newborn ( $<9$ days) & $2173(8.6)$ & $2531(8.8)$ \\
\hline Others & 3251 (12.9) & $402(1.4)^{*}$ \\
\hline
\end{tabular}

${ }^{*}$ Significant difference before and after intervention, $\mathrm{P}<0.001$.

Table 2 Admission according to diagnostic related group before (1996) and after (1999) implementation of medical emergency team ${ }^{\star}$

\begin{tabular}{lcc} 
Group & Before intervention & After intervention \\
\hline $\mathrm{II}$ & $1647(6.5)$ & $1945(6.7)$ \\
\hline $\mathrm{III}$ & $978(3.9)$ & $1324(4.6)$ \\
$\mathrm{IV}$ & $5902(23.4)$ & $5707(19.8)$ \\
\hline $\mathrm{V}$ & $2903(11.5)$ & $4945(17.2)$ \\
\hline $\mathrm{VII}$ & $3178(12.6)$ & $4116(14.3)$ \\
\hline $\mathrm{VIII}$ & $3343(13.3)$ & $3728(12.9)$ \\
\hline $\mathrm{IX}$ & $1136(4.5)$ & $1088(3.8)$ \\
\hline $\mathrm{X}$ & $2456(9.8)$ & $2619(9.1)$ \\
\hline
\end{tabular}

*Distribution of groups in 1996 and 1999 significant at $P<0.0001$. †Groups created from over 200 categories created by Commonwealth Department of Health and Family Services, 1999.

Table 3 Hospital mortality, incidence of cardiac arrest, and mortality from cardiac arrest before (1996) and after (1999) implementation of medical emergency team

\begin{tabular}{lcc} 
& $\begin{array}{c}\text { Before } \\
\text { intervention }\end{array}$ & After intervention \\
\hline Hospital deaths: & 380 & \\
\hline No of deaths & 19.67 & 393 \\
\hline Rate per 1000 patients & & $17.20^{*}$ \\
\hline Cardiac arrest: & 73 & \\
\hline No of cardiac arrests & 3.77 & $2.05^{*}$ \\
\hline Rate per 1000 patients & $56(76.7)$ & $26(55.3)^{\star}$ \\
\hline No (\%) of deaths & 45 & \\
\hline Unplanned admissions to intensive care: & & 78 \\
\hline No of admissions & 2.3 & 3.4 \\
\hline Rate per 1000 patients & $15(33.3)$ & $23(29.5)$ \\
\hline No (\%) of deaths &
\end{tabular}

${ }^{*}$ Significant difference before and after intervention, $\mathrm{P}<0.001$.

to emergency department (2.7, 1.7 to 4.5$)$; male patients (1.5, 1.1 to 2.2$)$; and same day admission (0.36, 0.2 to 0.6$)$ were all significantly associated with the risk of cardiac arrest (table 4). After adjustment for these factors the odds ratio for cardiac arrest with the medical emergency team in place was $0.50(0.35$ to 0.73$)$. 
Table 4 Independent predictors of cardiac arrest: multivariate analysis

\begin{tabular}{lccc} 
Risk factor & Unit & Coefficient (SE) & Odds ratio (95\% CI) \\
\hline MET & Yes & $-0.66(0.185)$ & $0.52(0.36$ to 0.74$)$ \\
\hline Age $\geqslant 65$ years & Yes & $2.09(0.212)$ & $8.07(5.32$ to 12.2$)$ \\
\hline Sex & Males & $0.41(0.183)$ & $1.51(1.05$ to 2.16$)$ \\
\hline Emergency admission & Yes & $1.01(0.259)$ & $2.73(1.65$ to 4.54$)$ \\
\hline Same day admission & Yes & $-1.02(0.223)$ & $0.36(0.23$ to 0.56$)$ \\
\hline MET=medical emergency team. & &
\end{tabular}

Distribution of calls for medical emergency team

During 1999 the team was called out 152 times for 124 patients; 21 patients had more than one call. Among the patients, 40 died. Two patients died during the team visit; 13 were allocated "do not resuscitate" orders during the team visit and subsequently died; 14 died during or after admission to intensive care or the coronary care unit; and 11 died in hospital in circumstances unrelated to the medical emergency team call. The mean age of the 124 patients was 60 (SD 17.4) years. Half of the calls originated from the general medical wards, followed by general surgery $(26 \%)$, orthopaedic surgery $(6 \%)$, cardiology $(4 \%)$, and thoracic surgery $(4 \%)$. Almost all calls were made by nurses $(84 \%)$ or junior medical officers (15\%).

\section{Discussion}

We found that early intervention by a medical emergency team reduced the incidence of unexpected cardiac arrest in hospital by about half. Furthermore, the subsequent mortality was reduced from $77 \%$ to $55 \%$ after the system had been introduced. In our hospital, this was a reduction in mortality by two patients per thousand hospital admissions.

Unexpected cardiac arrest is a serious and clinically important adverse event that carries a high mortality. ${ }^{56}$ Such an event is often preceded by signs of physiological deterioration, ${ }^{7-9}$ which indicates that it is often neither a sudden nor an unpredictable event. Early intervention when a patient shows signs of clinical instability could reduce the incidence of cardiac arrest and hence mortality.

Critically ill patients may be identified by clinical signs of dysfunction of the airway, breathing, or circulation. In our hospital the "traditional" system of management of these patients was hierarchical and depended on the skill, experience, judgment, and timely involvement of relevant staff members. These factors varied considerably and resulted in a poorly standardised and unstructured approach. ${ }^{9}$ Early intervention should prevent further deterioration to the point that a cardiac arrest call is made. Our observed reduction in calls and associated mortality is consistent with that conjecture.

The implementation of the response system required considerable cultural change throughout the hospital with an education programme and audit process, which could explain some of the observed effects. On the other hand, the potential effect could have been underestimated. During the early phase of implementation junior medical and nursing staff seemed unwilling to broach the traditional system of referral. There were probably still unexpected cardiac arrest calls and unplanned admissions to intensive care that could have been prevented by better use of the medical emergency team.
The new system may simply have transferred mortality associated with cardiac arrest calls to mortality that occurred at other times and other places. While two patients died during the team visit and 14 patients died after admission to intensive care or coronary care, these events did not fully account for the overall reduction in mortality. Nevertheless, even if this effect contributed to the entire reduction in the frequency of calls the team's response still allows for a more considered approach to the patient's management than the chaos that is often inevitable with a cardiac arrest call. Calls to the medical emergency team often resulted in discussion with the patient's consultant and a decision to implement on a "do not resuscitate" order with palliative care. This occurred in 17 patients, of whom 13 died.

\section{Comparison with other studies}

In a recent study, the six month incidence of cardiac arrest, mortality, and unplanned admissions to intensive care was found to be significantly lower in a hospital with medical emergency teams compared with two hospitals that had no such system. After adjustment for case mix, however, the difference was significant only for unplanned admissions to intensive care. $^{13}$ The results were attributed to poor use of the emergency team at the intervention hospital, and failure to identify patients who would benefit most from such early intervention. ${ }^{14}$ However, the comparisons between hospitals and statistical adjustments in that study were problematic and arguably less than optimal, making its results difficult to interpret.

\section{Strengths and limitations}

We used a before and after design within a hospital and with a historical control. We could control for all major characteristics associated with the hospital, and our inferences on cause and effect could be made with greater confidence than those made in a comparison between hospitals. Our end points were incidence of unexpected cardiac arrest call (irrespective of the cause of cardiac arrest) and mortality. These are well documented so error in measurement is unlikely to be an issue. Despite these strengths, the study was based on data from only one tertiary teaching hospital, in which organisational structures may be different from other hospitals in other regions and countries.

The use of two discontinuous time points could mean that the observed reduction in cardiac arrest calls could have resulted from a "natural regression" due to medical progress, or at worst, random fluctuation. This seems unlikely because data from 1994 to 2000 show that the incidence of cardiac arrests fell immediately. During the same period, the mortality in hospital also fell. When we analysed the data with a generalised linear model (for example, Poisson regression) the negative trend was significant at $\mathrm{P}<0.0001$ for both cardiac arrests and mortality.

The improvement in mortality could also be an indirect effect, unrelated to the medical emergency team-namely, the Hawthorne effect. ${ }^{15}$ The research project had a high profile within the hospital, and the authors' concerns were well known. Publication of preliminary results highlighted issues regarding delivery of service and became a focus for improvement in patient care. ${ }^{9}$ Also the employment of a full time research nurse to facilitate the implementation of the 


\section{What is already known on this topic}

In most studies mortality from unexpected cardiac arrest in hospital exceeds $50 \%$

Such events are usually preceded by signs of clinical deterioration in the hours before cardiac arrest

\section{What this paper adds}

Early intervention by a medical emergency team significantly reduced the incidence of and mortality from unexpected cardiac arrest in hospital

system may have improved the ward management of patients with clinical instability. The working relationship of the team nurse may also have altered patterns of referral to the team and hence, conceivably, mortality.

Nevertheless, irrespective of whether the 50\% reduction in cardiac arrest was brought about by the team itself or activities associated with the implementation of the system our results show that an early intervention based on well defined criteria of clinical instability together with a system of support, ongoing education, and performance feedback to the primary caregivers can significantly reduce the incidence of and mortality from cardiac arrest in hospital.

We thank Mary Draper from the Department of Human Services, Victoria, for the department's financial support and her enthusiasm for the project. We also thank the staff of Dandenong Hospital, who have made the commitment to better quality care for all our patients.

Contributors: MDB, GEM, SAB, BPW, and JNA contributed to the concept, design, and implementation of the study, drafted the manuscript, and read and approved the final version of the paper. TVN was involved in analysis and interpretation of data and drafting the manuscript. MDB, SAB, and BPW are guarantors.

Funding: Department of Human Services.

Competing interests: None declared.

1 Brennan TA, Leape LL, Laird NM, Hebert L, Localio AR, Lawthers AG Incidence of adverse events and negligence in hospitalized patients: results of the Harvard medical practice study I. $N$ Engl $J$ Med 1991;324:370-6.

2 Wilson RM, Runciman WB, Gibberd RW, Harrrison BT, Newby L, Hamilton JD. The quality in Australian health care study. Med J Aust 1995; 163:458-71

3 Leape LL, Brennan TA, Laird N, Lawthers Ag, Localio AR, Barnes BA. The nature of adverse events in hospitalized patients: results of the Harvard medical practice study II. N Engl J Med 1991;324:377-84.

4 Wilson RM, Harrison BT, Gibberd RW, Hamilton JD. An analysis of the causes of adverse events from the quality in Australian health care study. Med J Aust 1999;170:411-5.

5 Peatfield RC, Sillett RW, Taylor D, McNicol MW. Survival after cardiac arrest in hospital. Lancet 1977;i:1223-5.

6 Bedell SE, Delbanco TL, Cook EF, Epstein FH. Survival after cardiopulmonary resuscitation in the hospital. $N$ Engl $J$ Med 1983;309:569-76

7 Schein RM, Hazday N, Pena M, Rubens BH, Sprung CL. Clinical antecedents to in-hospital-cardiopulmonary arrest. Chest 1990;98:1388-

8 Franklin C, Mathew J. Developing strategies to prevent inhospital cardiac arrest: analyzing responses of physicians and nurses in the hours before the event. Crit Care Med 1994;22:244-7.

9 Buist MD, Jarmolowski E, Burton PR, Bernard SA, Waxman BP, Anderson J. Recognising clinical instability in hospital patients before cardiac arrest or unplanned admission to intensive care. A pilot study in a tertiary-care hospital. Med J Aust 1999;171:22-5.

10 Hourihan F, Bishop G, Hillman KM, Daffurn K, Lee A. The medial emergency team: a new strategy to identify and intervene in high risk patients. Clin Intensive Care 1995;6:269-72.

11 Lee A, Bishop G, Hillman KM, Daffurn K. The medical emergency team. Anaesth Intensive Care 1995;23:183-6.

12 SAS. SAS/STAT: user's guides, release 6.03. Cary, NC: SAS Institute, 1990:549-640.

13 Bristow PJ, Hillman KM, Chey T, Daffurn K, Jaques TC, Norman SL, et al. Rates of in-hospital arrests, deaths and intensive care admissions: the effect of a medical emergency team. Med J Aust 2000;173:236-40.

14 Kerridge RK. The medical emergency team: no evidence to justify not implementing change. Med J Aust 2000;173:228-9.

15 Campbell JP, Maxey VA, Watson WA. The Hawthorne effect: implications for pre hospital research. Ann Emerg Med 1995;26:590-4 